\title{
Experimental Investigation on Formability of AZ31B Magnesium Alloy V-Bending Under Pulse Current
}

\author{
Xing-Rong Chu ${ }^{1} \cdot$ Lei Wang $^{2} \cdot$ Shu-Xia Lin ${ }^{1} \cdot$ Zhen-Ming Yue ${ }^{1} \cdot$ Jun Gao ${ }^{1}$
}

Received: 3 January 2018/Revised: 8 February 2018/Published online: 27 April 2018

(C) The Chinese Society for Metals and Springer-Verlag GmbH Germany, part of Springer Nature 2018

\begin{abstract}
In this work, the influence of pulse current parameters on springback and bending force of magnesium alloy during electropulse-assisted (EPA) V-bending was investigated. The experimental results showed that pulse current can effectively reduce the springback and the bending force compared to the experiments without current. The frequency has a more significant influence on bending force and springback than electric current density. Electroplastic (EP) effect begins to work when pulse current parameters reach a threshold value. To explore the mechanism of EPA V-bending, the microstructure evolution and fracture surface of the bending specimen were studied. It was found that pulse current can promote the occurrence of dynamic recrystallization (DRX) of magnesium alloy compared to traditional hot forming process. The fracture mode of AZ31B under EPA V-bending evolves from brittle fracture to ductile fracture with increasing pulse current parameters. Based on the discussion of athermal and thermal effects of EP effect, the mechanism of pulse current to promote DRX is studied and athermal effect is proved to exist.
\end{abstract}

Keywords AZ31B alloy $\cdot$ Pulse current $\cdot$ Electroplastic (EP) effect $\cdot$ Springback $\cdot$ Dynamic recrystallization

\section{Introduction}

Magnesium alloys are a kind of attractive lightweight structural materials, which possess lower density, high specific strength, high specific stiffness and so on. They have been emerging as a potential candidate for several applications, especially in automobile and aerospace industries. However, their close-packed hexagonal structure limits the capacity of plastic deformation at room temperature, which has prevented them from widespread application in production $[1,2]$. Besides, they are usually formed to outward components with certain curvature to improve the aerodynamic performance [3]. However, springback phenomenon occurs inevitably during bending

Available online at http://link.springer.com/journal/40195

Zhen-Ming Yue

yuezhenming@sdu.edu.cn

1 Associated Engineering Research Center of Mechanics and Mechatronic Equipment, Shandong University, Weihai 264209, China

2 Weifang GeorTek Electronics Co., Ltd., Weifang 261205, China process. To reduce springback and improve the plasticity, warm forming has become a widely used method. Although warm forming can greatly improve the plasticity of magnesium alloys, it has many drawbacks such as high energy expense and oxidation. Electropulse-assisted (EPA) forming is considered as an advanced technology, which can reduce the springback and improve the formability of the workpieces [4].

Electroplastic (EP) effect was first discovered and reported by Troitskii and Likhtman in 1963 [5]. Based on a large number of researches, former soviet union scholars studied the interaction between dislocation and electronic and put forward the original model to explain the mechanism of EP effect [6-8]. Based on varieties of material experiments, Conrad [9-12] put forward the electronic wind mode theory to explain the mechanism of EP effect. Recently, the mechanism of EP effect has become a hot spot of research, and it is found that the EP effect is a combination of various physical effects which mainly include Joule heating effect, magnetic compression effect, pure electric plastic effect and skin effect. Magnetic compression effect and skin effect have little effect on EP effect and can be ignored basically [13]. Therefore, EP 
effect is mainly combined effect of pure electric plastic effect and Joule heating effect.

EP effect can effectively reduce flow stress, optimize microstructure and improve the formability of the materials [14]. EP effect has been applied to form difficult forming materials, such as magnesium and titanium alloys. Through EPA drawing and rolling of magnesium alloy, Tang et al. [15-18] found that pulse current can promote the movement and climbing of the dislocation, which is beneficial to open dislocation tangles and change dislocation density. Bao et al. [19] studied the EPA incremental forming of AZ31B alloy and found that pulse current can improve the formability and the athermal effect in EP effect was proved to exist. However, $\mathrm{Li}$ et al. [20] pointed out that Joule heating effect is significant and plays a main role in EP effect during EPA tensile and V-bending experiments of titanium alloy. Xu et al. [15] found that with the increase in frequency and RMS current density, flow stress of magnesium alloys decreases and the elongation of failure increases during EPA tensile test. Egea et al. [21] carried out EPA V-bending test based on a self-designed pulse current generator. Experimental results showed that pulse current can reduce the bending force and the springback angle. Moreover, it was found that the frequency influence on bending force is more significant than current density. Salandro et al. [22] studied the effect of pulse current density, pulse current cycle and pulse duration on the bending force and the springback angle and found that athermal effect in EP effect is proved to exist. Xie et al. [23] found that the pulse current can refine the grain and inhibit the occurrence of twins in the process of the V-bending.

In this work, with pulse current flowing through the specimen horizontally, with different punch downward displacements, two groups of EPA V-bending experiments of AZ31B alloy were carried out on a self-designed device. The formed bending specimens under different process parameters were obtained, and the forming forces and springback values were measured. The existence of athermal effect and the mechanism of dynamic recrystallization (DRX) under EP effect were investigated. The influence of root-mean-square (RMS) current density on bending force, springback angle and fracture behavior during bending was analyzed and discussed, respectively. The aim of this work is to provide a basis reference of the pulse current-assisted forming for AZ31B alloy bending.

\section{Experimental}

The materials used in this work were hot-rolled sheets of AZ31B alloy. Its chemical composition is listed in Table 1, and its original metallographic image is shown in Fig. 1.
Table 1 Chemical composition of AZ31B sheet (wt\%)

\begin{tabular}{lllllll}
\hline $\mathrm{Al}$ & $\mathrm{Zn}$ & $\mathrm{Mn}$ & $\mathrm{Si}$ & $\mathrm{Ca}$ & $\mathrm{Cu}$ & $\mathrm{Mg}$ \\
\hline $2.5-3.5$ & $0.6-1.4$ & $0.2-1.0$ & 0.08 & 0.04 & 0.01 & Bal. \\
\hline
\end{tabular}

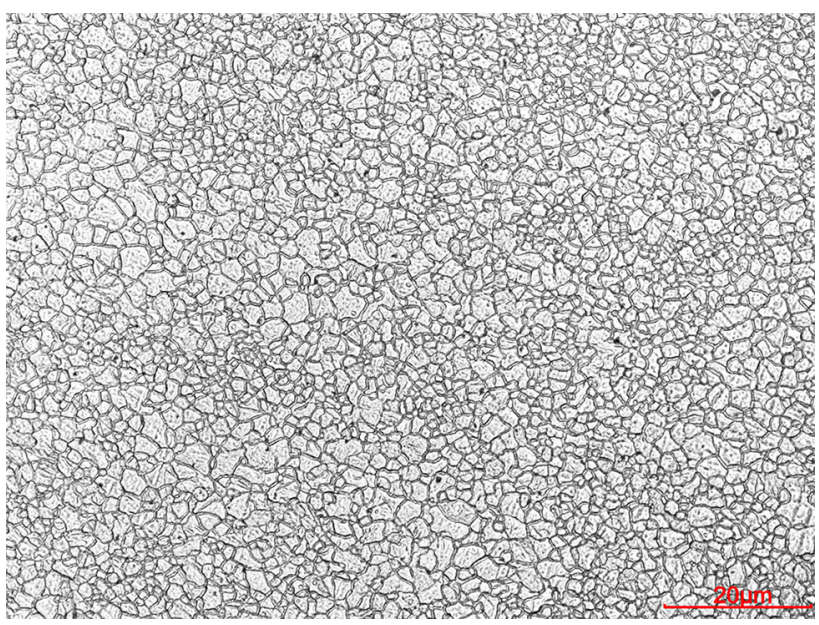

Fig. 1 Microstructure of original AZ31B sheet

The bending specimen size was $110 \mathrm{~mm} \times 20 \mathrm{~mm} \times 1.2$ $\mathrm{mm}$. The direction of V-bending was perpendicular to the rolling direction in this test.

In this work, a laboratory EPA V-bending experiment setup was designed as shown in Fig. 2. The punch radius was $4 \mathrm{~mm}$, and the bakelite plate was used for insulation. Pulse current flowed through the specimen horizontally during test. Electropulse was created by a THDM-1 highenergy electropulse generator. The waveform is shown in Fig. 3, and $t_{\mathrm{p}}$ is pulse period, $t_{\mathrm{i}}$ is pulse duration and $t_{\mathrm{o}}$ is pulse interval. During the experiments, the voltage and frequency can be adjusted to obtain different root-meansquare (RMS) current densities and peak current densities, which can be recorded directly by an oscilloscope. The relationship of RMS current $\left(I_{\mathrm{r}}\right)$ and peak current $\left(I_{\mathrm{p}}\right)$ can be expressed by Eq. (1),

$$
\begin{aligned}
& \int_{0}^{t_{\mathrm{i}}} R I_{\mathrm{p}}^{2} \sin ^{2} \frac{\pi}{t_{\mathrm{i}}} \mathrm{d} t=I_{\mathrm{r}}^{2} R t_{\mathrm{p}}=\frac{I_{\mathrm{r}}^{2} R}{f} \\
& \Rightarrow I_{\mathrm{r}}=I_{\mathrm{p}} \sqrt{\frac{f t_{\mathrm{i}}}{2}}
\end{aligned}
$$

where $I_{\mathrm{p}}$ is the peak current, $I_{\mathrm{r}}$ is the RMS current, $R$ is the materials resistance, $t_{\mathrm{i}}$ is the pulse duration, $t_{\mathrm{p}}$ is the pulse period, $f$ is the pulse frequency. The EPA V-bending tests were carried out in a CMT5303 electronic universal testing machine with a punch speed of $10 \mathrm{~mm} / \mathrm{min}$. The displacement-bending force curves were recorded during the test. To measure the specimen temperature, a thermocouple 

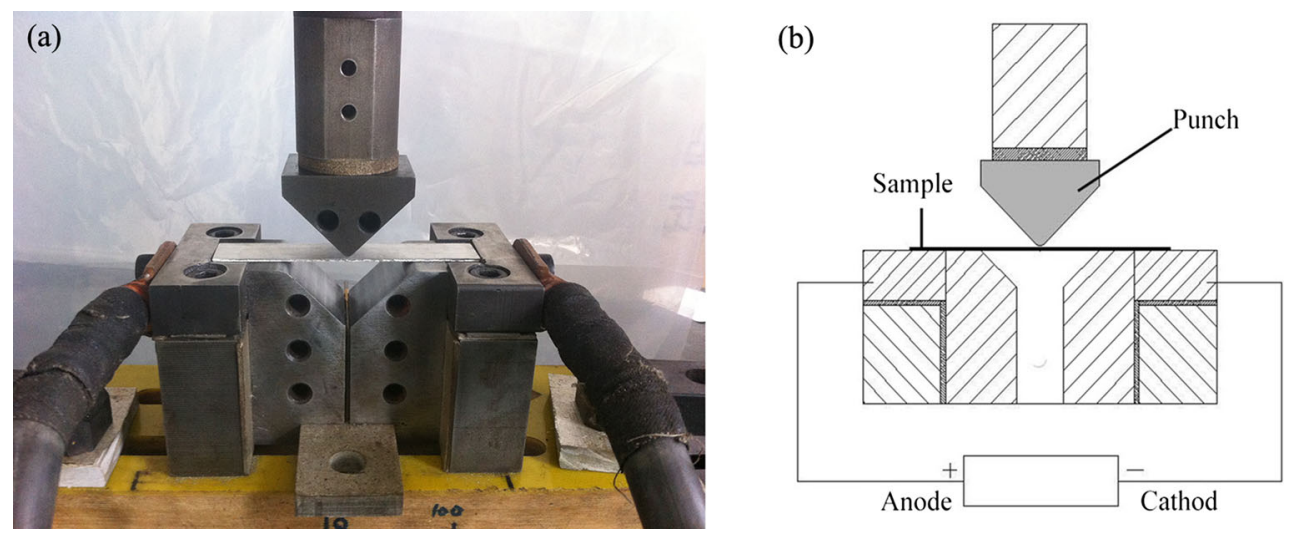

Fig. 2 Experiment setup and its schematic diagram: a experiment setup, b setup schematic diagram

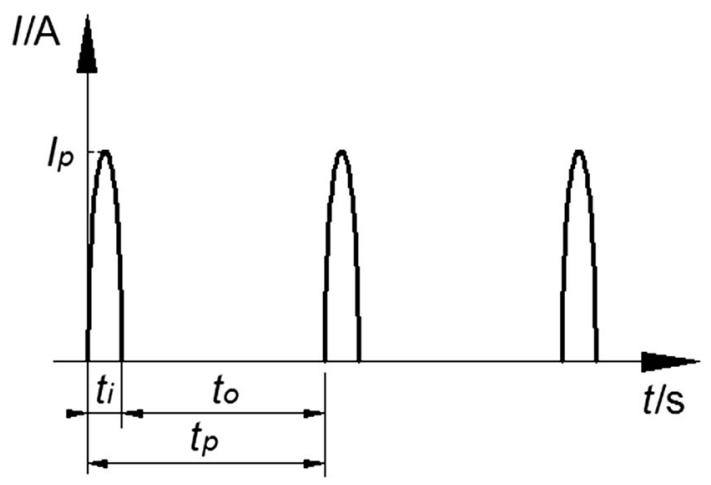

Fig. 3 Pulse current waveform in the experiment

was welded in the main deformation zone of specimen and the temperature was recorded by a multichannel temperature detector during the test. The forming angle of V-bending specimen after test was measured by the universal protractor.

Experimental results showed that fracture occurred when punch displacement reached $23.5 \mathrm{~mm}$ under room temperature. However, when punch displacement was less than $21 \mathrm{~mm}$, specimen could be formed without fracture. In this work, punch displacement of $21 \mathrm{~mm}$ (Group I) was set to study pulse current influence on bending force and springback angle. And punch displacement of $23.5 \mathrm{~mm}$ (Group II) was used to analyze specimen fracture mechanism. To avoid electric discharge, pulse current was applied when punch contacted specimen and moved downwards $1 \mathrm{~mm}$. Each test was repeated at least three times. The specimen microstructures and fracture morphology were studied by Axio Lab A1 optical microscope and Nova NanoSEM 450 scanning electron microscope, respectively. The metallographic samples were taken from the main deformation zone after V-bending, and fracture analysis samples were taken from the fracture location.

\section{Results and Discussion}

The adopted pulse current parameters and forming results of Groups I and II are shown in Table 2. The forming angle is the angle of two straight flanges after bending. Forming angle of specimen without current (No. 0) is taken as a benchmark, and the springback angle is the difference between measured forming angle value and the reference value. The measured specimen temperatures are shown in Fig. 4. When pulse current is $50 \mathrm{~V}-200 \mathrm{~Hz}$, specimen temperature only reaches to $59.3{ }^{\circ} \mathrm{C}$. With electrical parameter increases from $70 \mathrm{~V}-200 \mathrm{~Hz}$ to $70 \mathrm{~V}-350 \mathrm{~Hz}$, the temperature peak value varies from $91.7^{\circ} \mathrm{C}$ to $141.6^{\circ} \mathrm{C}$. The highest measured temperature in the test was $195.7^{\circ} \mathrm{C}$.

The specimens after EPA V-bending of Group I are shown in Fig. 5; it is found that the forming angle decreases with the increase in RMS current, showing a different decreasing rate. Figure 6a presents the specimens after EPA V-bending (Group II). It is shown that with the increase in RMS current density, the cracks on specimens are decreased, with suitable electrical parameters, and bending specimens without cracks can be obtained. As listed in Table 2, the RMS current density of $13.02 \mathrm{~A} / \mathrm{mm}^{2}$ is the threshold value, when RMS current density is beyond this value, specimens after EPA V-bending show no cracks and the springback angle remains stable. The comparison of specimen without current and with a RMS current density of $13.02 \mathrm{~A} / \mathrm{mm}^{2}$ is shown in Fig. 6b. The specimen without current shows obvious crack, while specimen with current is in good forming condition. Under EP effect, the forming specimens show good bending quality, which proves that the pulse current can improve the formability of AZ31B alloy.

The force-displacement curves are shown in Fig. 7. It is known that springback value is proportional to the material yield strength and inversely proportional to elasticity 
Table 2 Experimental results under different forming conditions

\begin{tabular}{lllllll}
\hline Sample & Voltage $(\mathrm{V})$ & Frequency $(\mathrm{Hz})$ & $J_{\mathrm{r}}\left(\mathrm{A} / \mathrm{mm}^{2}\right)$ & $J_{\mathrm{p}}\left(\mathrm{A} / \mathrm{mm}^{2}\right)$ & \multicolumn{2}{c}{ Measured forming angle $\left(^{\circ}\right)$} \\
\cline { 5 - 7 } & & & & - & Group I & Group II \\
\hline 0 & - & - & - & 83.3 & 107.1 & Fracture (A) \\
1 & 50 & 200 & 8.5 & 100 & 98.6 & Fracture (B) \\
2 & 70 & 200 & 11.83 & 100 & 89.8 & Fracture (C) \\
3 & 70 & 350 & 13.02 & 110 & 87.8 & $78.9^{\circ}(\mathrm{E})$ \\
4 & 80 & 350 & 13.42 & 100 & 83 & $78.8^{\circ}(\mathrm{F})$ \\
5 & 70 & 450 & 15.56 & 116 & 81.0 & $77.8^{\circ}(\mathrm{G})$ \\
6 & 90 & 350 & & & & \\
\hline
\end{tabular}

$J_{\mathrm{r}}$ represents RMS current density, $J_{\mathrm{p}}$ represents peak current density. No. 0 represents specimen without current

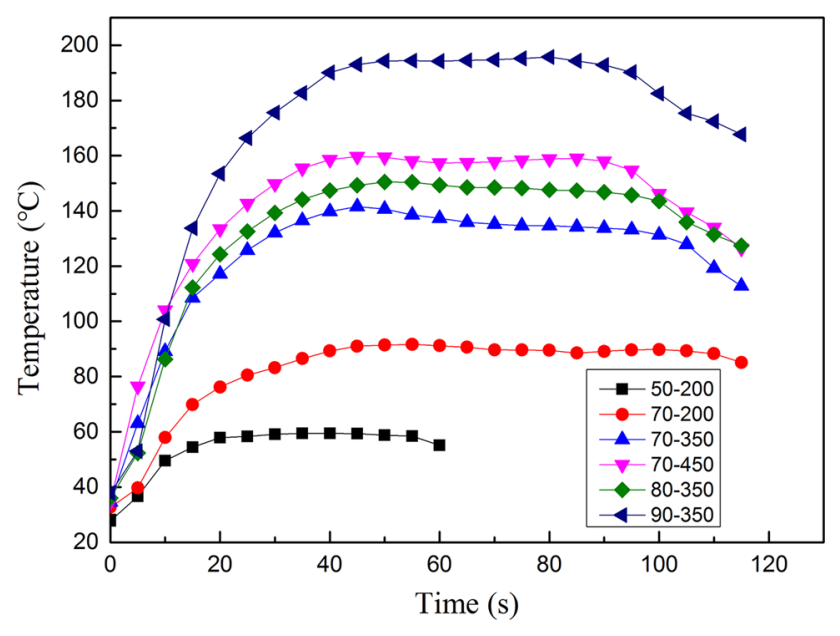

Fig. 4 Measured specimens temperature curves under different electrical parameters

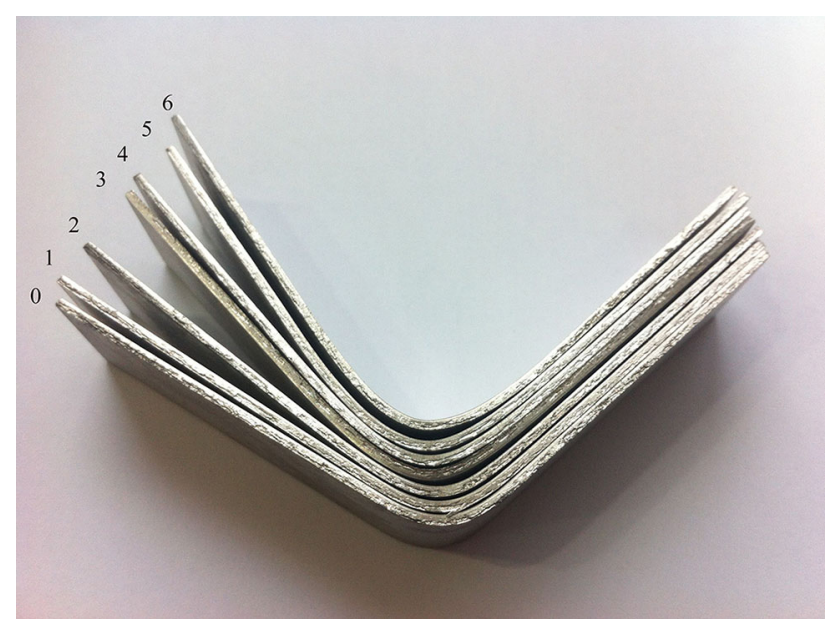

Fig. 5 Specimens after EPA V-bending (Group I)

modulus. According to Fig. 7a, the curves are basically coincidence under elastic deformation stage, indicating that the pulse current has little influence on elastic modulus.
Moreover, with the increase in electric parameters, yield strength decreases. Hence, pulse current can decrease the springback value through lowering yield strength in EPA V-bending. Meanwhile, force curves of Fig. 7a show that strain hardening causes the increase in bending force in initial bending stage, due to thermal softening caused by EP effect, and the curves show a saturation characteristic with increasing deformation. When V-bending process entered into curvature correction phase, the bending force increased rapidly.

Figure 7b shows the force-displacement curves of Group II. It is shown that, for certain electrical parameters, the bending force shows a suddenly force drop and then increases at the end of the bending stage, which indicates the occurrence of fracture in the specimen. The much of the force drops, the serious the fracture is. The force increases after fracture is caused by the interaction between the die and the punch.

The influences of RMS current density on bending force and springback angle were obtained as shown in Fig. 8. The bending force was the measured stable value with punch displacement of $12.5 \mathrm{~mm}$. As shown in Fig. 8, when $J_{\mathrm{r}}$ reaches to $6.5 \mathrm{~A} / \mathrm{mm}^{2}$, EP effect is not significant and pulse current has little influence on bending force and springback angle compared to experiment without current. With the increase in RMS current density, EP effect begins to function, and bending force and springback angle reduce significantly. When $J_{\mathrm{r}}$ reaches to $13.02 \mathrm{~A} /$ $\mathrm{mm}^{2}$, bending force is reduced by $43.31 \%$ and springback angle is decreased by $18.57 \%$ compared to the specimen without current. When $J_{\mathrm{r}}$ varies from 13.02 to $15.56 \mathrm{~A} /$ $\mathrm{mm}^{2}$, bending force is reduced by $32.92 \%$ and springback angle is decreased by $7.79 \%$. It is indicated that there exists a threshold value [24] for EP effect. For low RMS current, the EP effect has little influence on AZ31B plasticity, and when RMS current exceeds a certain value, the influence of the EP effect on bending force and springback angle is improved significantly. What is more, 


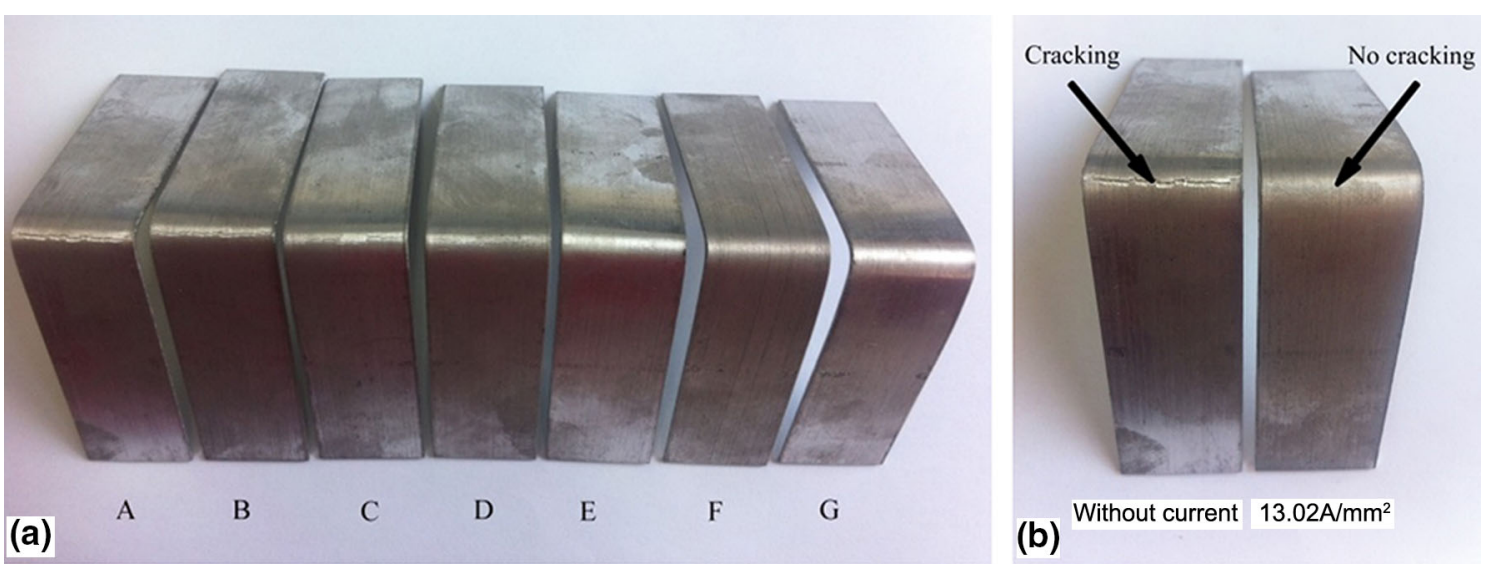

Fig. 6 V-bending (Group II): a different electropulse parameters, b without current and $J_{\mathrm{r}}=13.02 \mathrm{~A} / \mathrm{mm}^{2}$
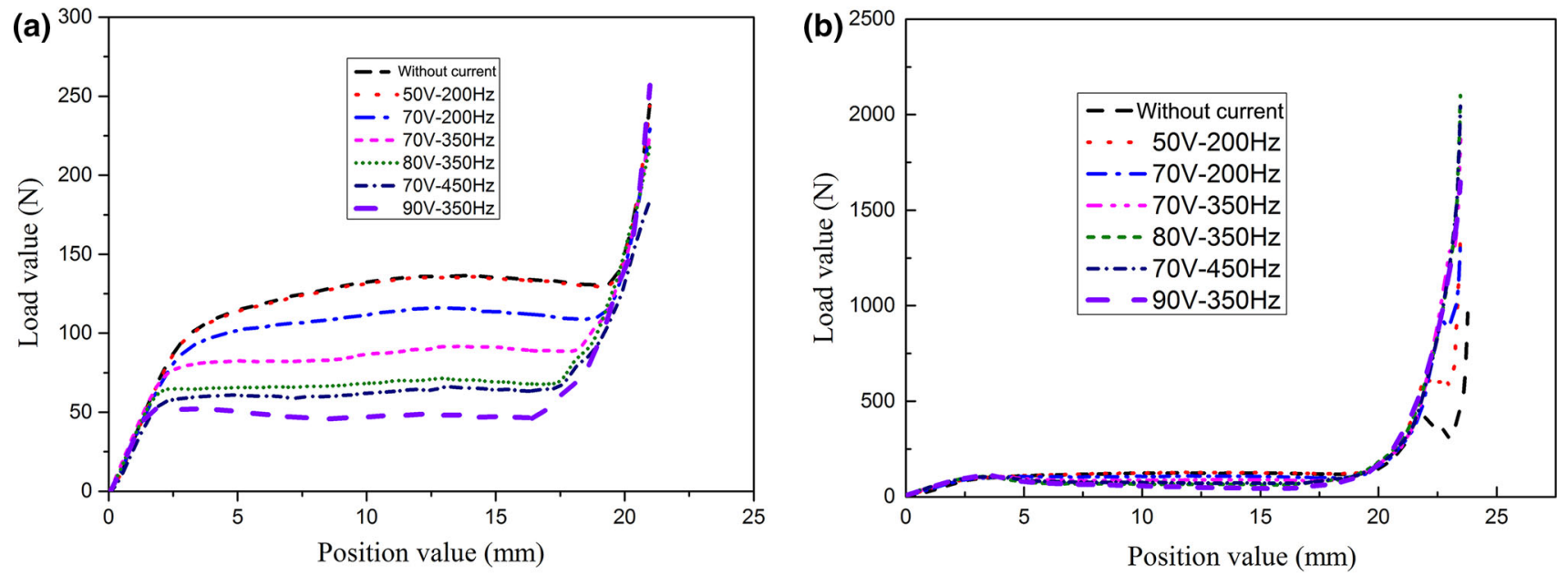

Fig. 7 Force-displacement curves under different current parameters: a Group I, b Group II

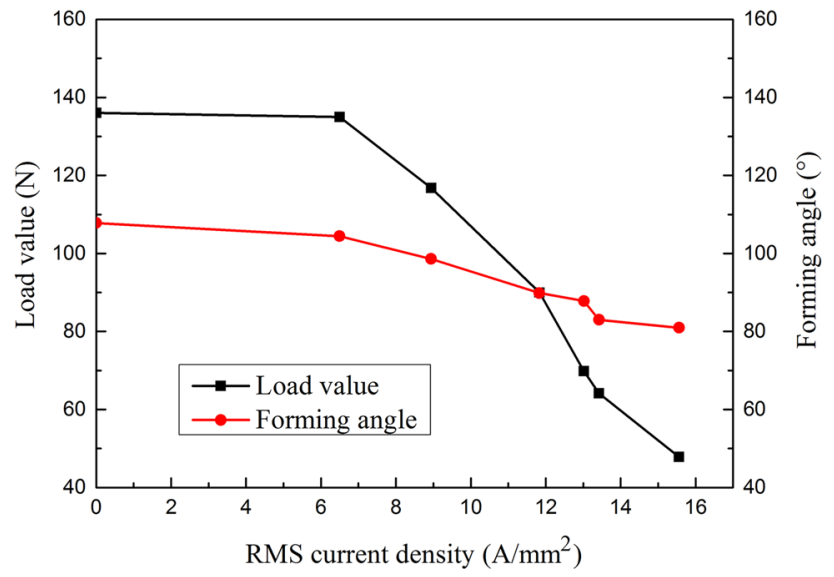

Fig. 8 Influences of RMS current density on bending force and springback angle

it was found that pulse current has a greater effect on the reduction in bending force than in springback angle, which consists with Ref. [20].

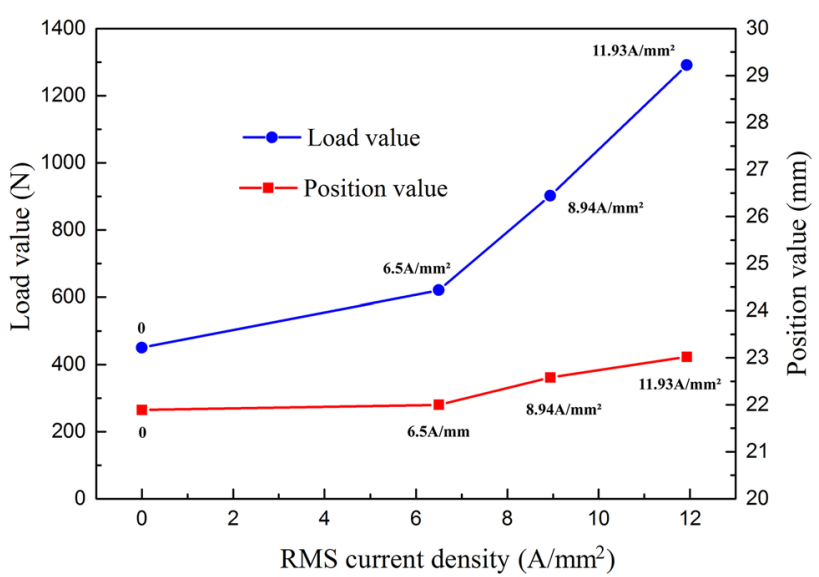

Fig. 9 Fracture position and fracture force under different RMS current densities

The fracture position and fracture force under different RMS current densities during V-bending (Group II) are shown in Fig. 9. Due to EP effect, the formability of 
AZ31B alloy is increased. The specimen cracking position is delayed with the increase in RMS current density. When the electric parameter is above $80 \mathrm{~V}-350 \mathrm{~Hz}(13.02 \mathrm{~A} /$ $\mathrm{mm}^{2}$ ), good bending specimens are obtained and no force drop is observed as shown in Fig. $7 b$.

To carry out the comparison test, traditional hot bending was carried out. As shown in Fig. 10, similar heating rate was obtained by adjusting traditional forming temperature through heater and heat conduction. The highest temperature of hot bending specimen is higher than that under EPA bending test. For force evolution, it is shown that the EPA bending force is lower than the traditional hot bending even with a lower forming temperature. Hence, the existence of athermal effect of electrical pulses is proved.

To study microstructure evolution during EPA V-bending and investigate DRX promotion mechanism under pulse current, the center area of V-bending sample (Nos. 0, 1, 3, 4, 6) was selected as the main deformation part, both inside and outside of the samples were taken to carry out the metallographic analysis, as shown in Fig. 11. Figure 11-No. 0 is the microscopic structure without current. For V-bending process, the outer region is under tensile deformation, while the inner region is under compressive deformation. The twinning is likely to be activated due to a compressive stress parallel to the basal plane in the inner region. Hence, a large number of twins can be found in the inner region, and the grains appear asymmetry and some coarse grains are found. While for the outer region, only a little twin can be found in some coarse grains. The microstructure with pulse current of $50 \mathrm{~V}-200 \mathrm{~Hz}$ and RMS current density of $6.5 \mathrm{~A} / \mathrm{mm}^{2}$ is shown in Fig. 11-No. 1. Compared to No. 0 , the bending force and springback angle have no obvious change, plenty of twins are observed in the inner region and a little twin can be found in some coarse grains in the outer region. The EP effect under these
Fig. 11 Microstructure images under different forming conditions: (0) after bending without current; (1) $50 \mathrm{~V}, 200 \mathrm{~Hz}$; (3) $70 \mathrm{~V}$, $350 \mathrm{~Hz}$; (4) $80 \mathrm{~V}, 350 \mathrm{~Hz}$; (6) $90 \mathrm{~V}, 350 \mathrm{~Hz}$. EX, IN represent extrados and intrados of specimen, respectively

electric parameters is not obvious. The highest temperature of the specimen is only $59.3{ }^{\circ} \mathrm{C}$ (Fig. 4) during the whole bending process. The EP effect has not reached the threshold value and has little effect on the plasticity of AZ31B alloy.

The microstructure of $70 \mathrm{~V}-350 \mathrm{~Hz}$ and RMS current density of $11.83 \mathrm{~A} / \mathrm{mm}^{2}$ is shown in Fig. 11-No. 3. The highest temperature of the specimen is $141.6^{\circ} \mathrm{C}$. In the inner region, some fine equiaxed grains are found in the boundary of some coarse grains and some sub-grains, which indicates that DRX has begun to occur. Meanwhile, the slip is still the dominant deformation mechanism in the outer region. Robson et al. [25] found that the critical resolved shear strain of slip is greater than that of the twin, so the inside compression area is likely to deform than the outside tensile area. For magnesium alloys, DRX is likely to occur when lots of dislocation piles up [26]. And it is found that DRX occurs earlier in the inside than that in the outside during EPA V-bending for AZ31B alloy. Buruni et al. [27] pointed out that DRX of magnesium alloy occurred at $200{ }^{\circ} \mathrm{C}$ under traditional forming process. In this work, as presented above, when temperature is only $141.6^{\circ} \mathrm{C}$, DRX begins to occur in the inner region, which indicates that pulse current can promote the DRX under a relative low temperature. With the increase in RMS current density, the highest temperature of No. 4 specimen reaches to $150.5^{\circ} \mathrm{C}$. For this condition, some fine equiaxed grains are found along the coarse grain boundary and DRX begins to occur in the outer region, while DRX is basically completed in the inner region. For No. 6 specimen, the
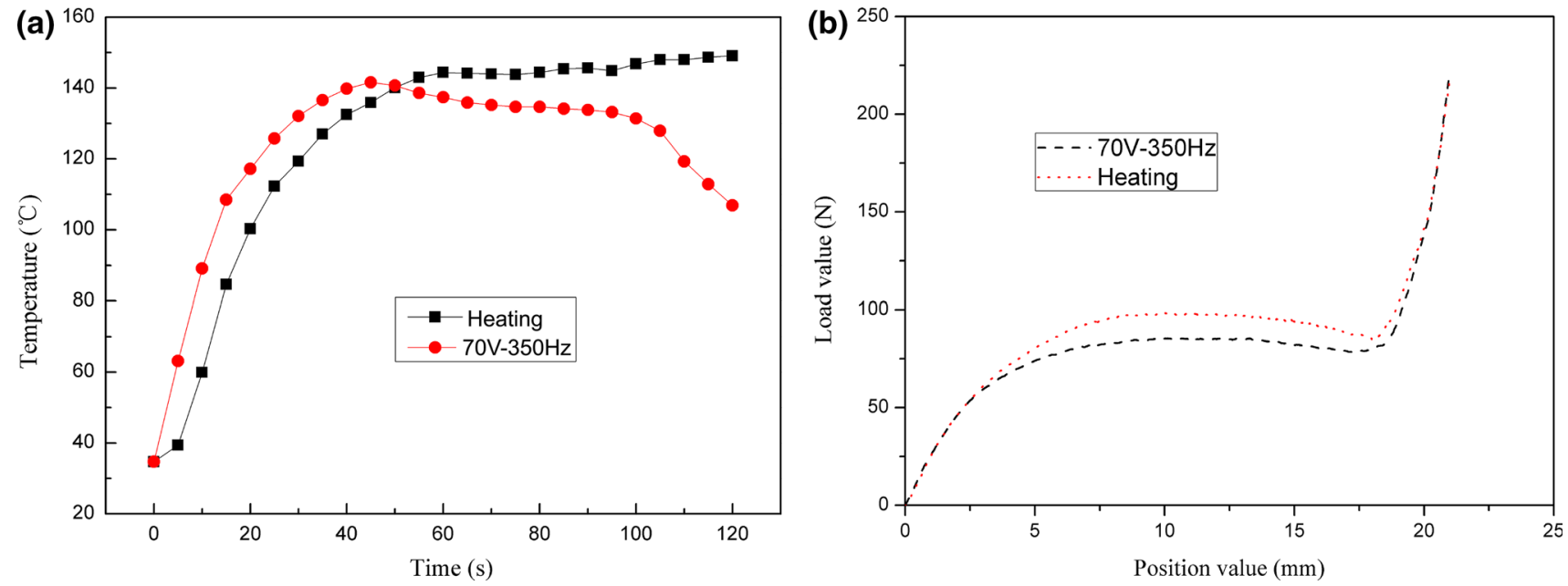

Fig. 10 Temperature a and bending force $\mathbf{b}$ evolution under traditional hot and EPA bending 

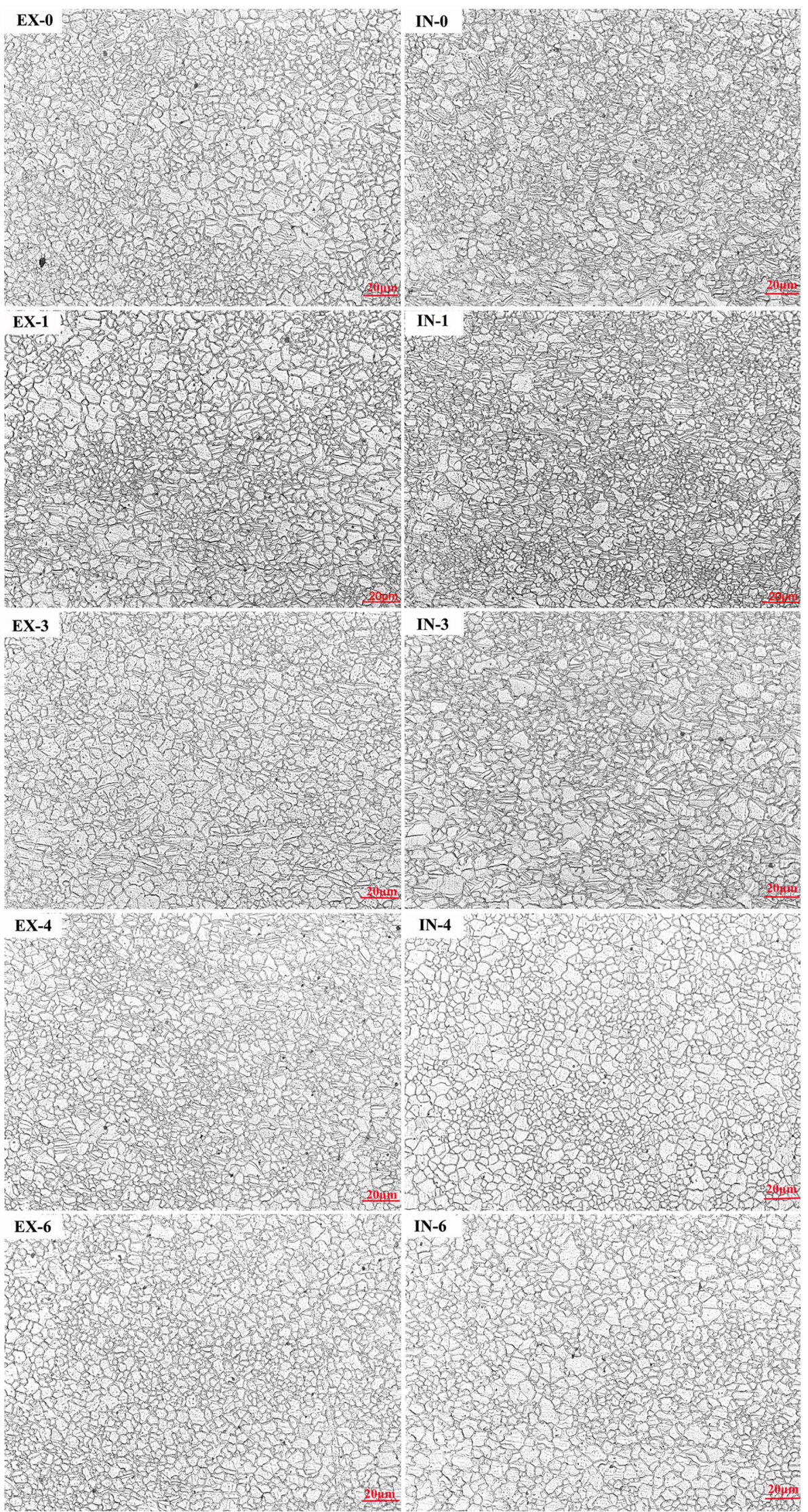

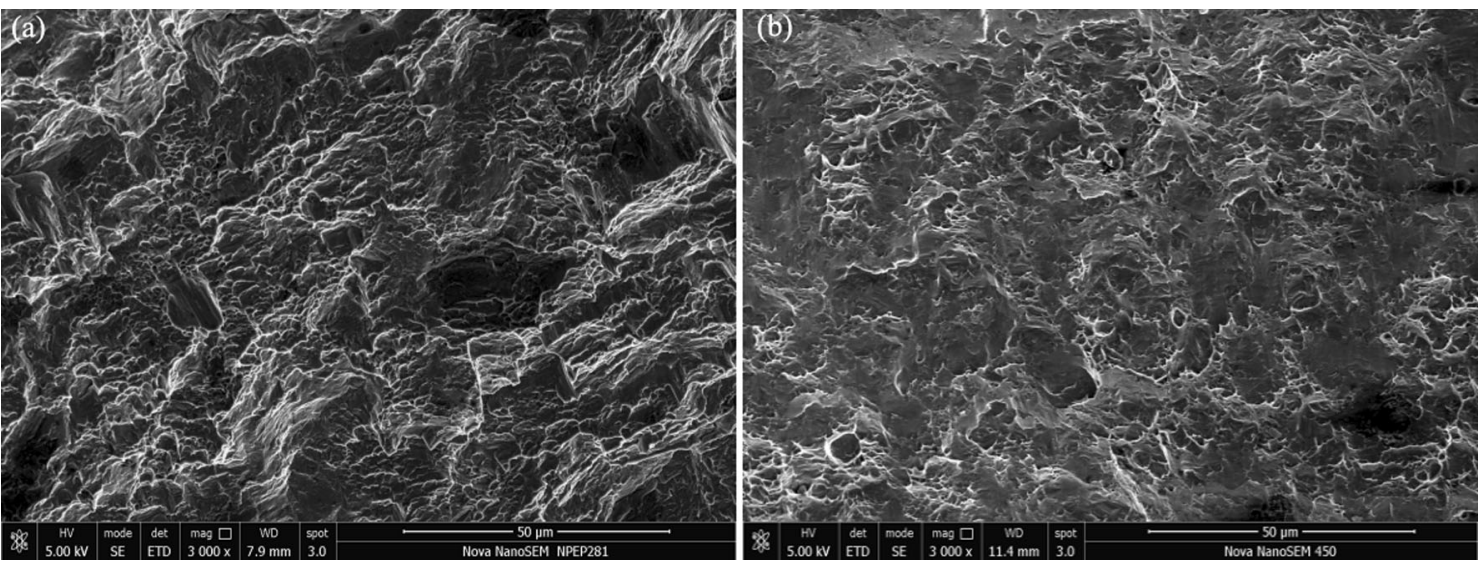

Fig. 12 Fracture morphology of specimens in Group II: a without current, b RMS current density of $11.83 \mathrm{~A} / \mathrm{mm}^{2}$

highest temperature is $195.7^{\circ} \mathrm{C}$, DRX process is completed in both inner region and outer region and the grains have grown up obviously in the inner region. It can be concluded that pulse current can promote the DRX of AZ31B alloy under lower temperature and optimize the microstructure. Hence, for No. 6 test condition, the material formability is improved, bending force is dropped by $61.73 \%$ and springback angle is reduced by $24.91 \%$ compared to the specimen without current.

In order to study the influence of pulse current on the fracture of magnesium alloy during EPA V-bending, fracture morphology was studied as shown in Fig. 12. Figure 12a is the fracture morphology without pulse current, and Fig. $12 \mathrm{~b}$ is the fracture morphology with a RMS current density of $11.83 \mathrm{~A} / \mathrm{mm}^{2}$. A large amounts of cleavage planes and short tear ridges can be seen in the fracture position in Fig. 12a, which is a typical feature of brittle fracture. However, as shown in Fig. 12b, when a RMS current density of $11.83 \mathrm{~A} / \mathrm{mm}^{2}$ is applied, the fracture morphology is different. The number of cleavage planes decreases and lots of dimples are found, which indicates a ductile fracture. From the microscopic view, it can be concluded that the formability of AZ31B alloy can be improved with the influence of appropriate pulse current.

\section{Conclusions}

1. EP effect can promote the dynamic recrystallization of AZ31B alloy under lower temperature compared to traditional hot forming process.

2. The pulse current can improve the bending formability of AZ31B alloy and reduce springback angle and bending force. EP effect has a threshold value; when RMS current density exceeds $13.02 \mathrm{~A} / \mathrm{mm}^{2}$, bending force is reduced by $43.31 \%$ and springback angle is decreased by $18.57 \%$ compared to test without current.
3. Athermal effect is proved to exist for EP effect of AZ31B alloy.

Acknowledgement The authors would like to acknowledge the financial support from the Natural Science Foundation of Shandong Province (No. ZR2016EEM25).

\section{References}

[1] Z.Y. Jin, N.N. Li, K. Yan, Acta Metall. Sin. (Engl. Lett.) 31, 71 (2018)

[2] L. Wang, Y.Q. Zhao, H.M. Chen, J. Zhang, Y.D. Liu, Y.N. Wang, Acta Metall. Sin. (Engl. Lett.) 31, 63 (2018)

[3] X. Han, S. Zhang, Z. Rong, Trans. Nonferr. Met. Soc. China 22, $416(2012)$

[4] O.A. Troitskii, A.G. Rozno, Sov. Phys. Solid. State 12, 161 (1970)

[5] O.A. Troitskii, V.I. Likhtman, Kokl. Akad. Nauk. SSSR 148 $332(1963)$

[6] O.A. Troitskii, Mater. Sci. Eng., A 75, 37 (1985)

[7] O.A. Troitskii, Strength Mater. 9, 35 (1977)

[8] O.A. Troitskii, Ind. Lab. (USSR) 51, 834 (1985)

[9] H. Conrad, A.F. Sprecher, W.D. Cao, JOM-US 42, 28 (1990)

[10] H. Conrad, Mater. Sci. Eng., A 322, 100 (2002)

[11] K. Okazaki, M. Kagawa, H. Conrad, Scr. Mater. 12, 1063 (1978)

[12] K. Okazaki, M. Kagawa, H. Conrad, Scr. Mater. 13, 473 (1979)

[13] K. Okazaki, M. Kagawa, H. Conrad, Mater. Sci. Eng., A 45, 109 (1980)

[14] R.S. Qin, A. Rahnama, W.J. Lu, X.F. Zhang, Mater. Sci. Technol. 30, 1040 (2014)

[15] Q. Xu, G.Y. Tang, Y.B. Jiang, Mater. Sci. Eng., A 528, 4431 (2011)

[16] Z.H. Xu, G.Y. Tang, S.Q. Tian, D. Fei, H.Y. Tian, J. Mater. Process. Technol. 182, 128 (2007)

[17] Y.B. Jiang, L. Guan, G.Y. Tang, C.H. Shek, Z.H. Zhang, Mater. Sci. Eng., A 528, 5627 (2011)

[18] X.P. Li, G.Y. Tang, J. Kuang, X.H. Li, J. Zhu, Mater. Sci. Eng., A 612, 406 (2014)

[19] W.K. Bao, X.R. Chu, S.X. Lin, J. Gao, Mater. Des. 87, 632 (2015)

[20] X.F. Li, Q. Zhou, S.J. Zhao, J. Chen, Procedia Eng. 81, 1799 (2014) 
[21] A.J.S. Egea, H.A.G. Rojas, D.J.J. Celentano, J.A. TraviesoRodríguez, J.L.I. Fuentes, J. Mater. Process. Technol. 214, 2261 (2014)

[22] W.A. Salandro, C. Bunget, L. Mears, J. Manuf. Sci. Eng. 133, 041008 (2011)

[23] H.Y. Xie, Q. Wang, K. Liu, P. Feng, X.H. Dong, J.F. Wang, J. Mater. Process. Technol. 215, 321 (2015)
[24] J.S. Andrawes, T.J. Kronenberger, T.A. Perkins, J.T. Roth, Mater. Manuf. Process. 22, 91 (2007)

[25] J.D. Robson, N. Stanford, M.R. Barnett, Acta Mater. 59, 1945 (2011)

[26] Y. Yan, W.P. Deng, Z.F. Gao, J. Zhu, Z.J. Wang, X.W. Li, Acta Metall. Sin. (Engl. Lett.) 29, 163 (2016)

[27] C. Bruni, A. Forcellese, F. Gabrielli, M. Simoncini, J. Mater. Process. Technol. 210, 1354 (2010) 